\title{
Introduction to the symposium: seed as a commons-exploring innovative concepts and practices of governing seed and varieties
}

\author{
Stefanie Sievers-Glotzbach ${ }^{1}\left[\right.$. Anja Christinck ${ }^{2,3}$
}

Accepted: 6 October 2020 / Published online: 20 October 2020

(c) The Author(s) 2020

\begin{abstract}
This Symposium explores how the theory of commons can be used to study, conceptualize and transform governance models for seed and plant varieties to counter ongoing trends towards agrobiodiversity loss and concentration of economic and political power in farming and food systems. Contributions to the Symposium present case studies from a range of geographical and socio-cultural contexts from the Global North and South. They show how seed and varieties relate to various known commons categories, including natural resource commons, knowledge and cultural commons, and global commons. Elements of these categories need to be integrated to gain a deeper understanding of Seed Commons, including the specific challenges that arise from the fact that seed, although a biological asset, is at least partly shaped by human selection driven by values, knowledge and needs of users. Collective responsibility, sharing of knowledge and seed, protection from private enclosure, and distributed, polycentric governance are key features of Seed Commons. The notion of 'commoning' focuses on the social practices and processes that create and sustain commons. Conceptualizing Seed Commons in their complexity offers initial starting points for policies and legal frameworks conducive to releasing the transformative power of Seed Commons for advancing sustainable farming and food systems.
\end{abstract}

Keywords Commons $\cdot$ Seed systems $\cdot$ Plant genetic resources $\cdot$ Intellectual property rights $\cdot$ Governance

\section{Introduction: Seed Commons-bringing together age-old traditions and new visions}

Since the dawn of agriculture, people have saved, stored, and shared seed of plants that were useful to them and sought to enhance their value. The inherent genetic properties of seeds, shaped by a mix of individual and collective human actions interacting with natural-selection forces at a given locality, determine their 'usefulness' in such aspects as yield and quality that impact human health and well-being.

The impressive variety of plants currently used to fulfill our various needs, including food, feed, fuel, fiber, and pharmaceutics, is a living testimony of the abilities of farmers

Stefanie Sievers-Glotzbach

stefanie.sievers-glotzbach@uol.de

1 Department of Business Administration, Economics and Law, University of Oldenburg, Oldenburg, Germany

2 Seed4change Research \& Communication, Gersfeld, Germany

3 German Institute for Tropical and Subtropical Agriculture (DITSL), Witzenhausen, Germany and farming communities to effectively breed and manage seed. Schöley and Padmanabhan (2017) describe agrobiodiversity as "an evident outcome of a long-lasting humannature relationship", or a "social-ecological artifact". Seed of crops, with its genetic properties and survival in agroecosytems dependent to a great extent on human management, thus differs from other 'natural' resources in important aspects.

With the emergence of 'modern' science-based plant breeding, the relationship between humans and plants has fundamentally changed. Seed delivery to farmers tends to be conceived as an 'industry', where different steps, like breeding, seed production and dissemination, are performed by different but interdependent actors, having shared as well as diverging interests (Christinck et al. 2014). Plant breeding in particular has become a highly specialized activity, involving high financial investmentsand risks. As a result, there has been ongoing pressure towards horizontal as well as non-horizontal mergers and alliances. Companies with activities in similar domains are merging to benefit, for example, from different geographic foci or larger product portfolios, whereas others 
are exploiting complementarities arising from activities in different domains, such as in seeds, GM technology and agrochemicals (OECD 2018). Today, three internationally operating companies control over $60 \%$ of the global commercial seed market (Howard 2015; Bonny 2017).

The consolidation of seed markets, along with political influence of the few global 'players' on political agendas and regulatory frameworks, has important consequences for the sustainability of food and seed systems. The International Panel of Experts IPES-Food, for example, raised attention to farmers' increasing dependence on a handful of suppliers, R\&D efforts concentrated on only a few crops of importance to global seed markets, and a more limited range of varieties being developed (IPES Food 2016,2017). The ongoing replacement of traditional crops and varieties by a limited number of 'modern' ones has led to rapid genetic erosion (Pautasso et al. 2013; Barbieri and Bocchi 2015); losses of crop genetic diversity, along with losses of associated species and degradation of related agroecosystems, also result in reductions in regulating and cultural ecosystem services, such as resilience to environmental changes and biological pest and disease control (Ficiciyan et al. 2018; FAO 2019).

At the international level, global trends of biodiversity loss, including that of cultivated plants, has led to international agreements such as the Convention on Biological Diversity (CBD) and the International Treaty on Plant Genetic Resources for Food and Agriculture (ITPGRFA). The ITPGRFA establishes, among the Contracting Parties, a system of collective governance for the genetic resources of some of the world's most important crops. It further acknowledges the role of farmers regarding their past, present and future contributions to the conservation and sustainable use of plant genetic resources for food and agriculture (PGRFA), which forms the basis of Farmers' Rights (FAO 2009). The ITPGRFA does not build on a concept of 'ownership'; it states that PGRFA are "a common concern of all countries" (FAO 2009), given the fact that all countries nowadays depend on PGRFA that originated elsewhere. Therefore, the system has been described as a Global Commons (Halewood 2013).

At the local level, growing concerns that concentration of market power, private interests and influence of global 'players' on political agenda-setting undermine democratic governance of food systems has given rise to worldwide social movements to 'free' seeds and reclaim global seed supply (see, for example, Schapiro 2018). Reservations concern both the use of certain molecular breeding techniques, with associated fears of negative impacts on human health and the environment, and the reliance of business model on intellectual property rights (IPR) that give the holders of such rights the power to control who can make use of certain plant varieties, single traits, or technologies.
In response to these concerns, a range of new social practices and bottom-up initiatives taken by peasant farmers, NGOs and interested individuals have emerged in the Global North and South. They build on innovative forms of community governance of seeds and varieties to enhance food sovereignty, farmer empowerment and sustainable agriculture (e.g., Pautasso et al. 2013; Kloppenburg 2014; Girard and Frison 2018). In many cases such initiatives explicitly build on farmers' age-old traditions of selecting, saving and exchanging seeds, as with community seed banks or seed savers' networks (Thomas et al. 2011; Pautasso et al. 2013; Vernooy et al. 2014; Coomes et al. 2015). Often these initiatives cooperate with public breeding and research institutes, e.g. in participatory plant breeding (Sperling et al. 2001; Almekinders et al. 2007; Dawson et al. 2008).

The growing movement of 'open source' seed (Aoki 2009; Kloppenburg 2014; Kotschi and Horneburg 2018; Montenegro de Wit 2019) is another expression of the above-mentioned concerns that makes reference to 'opensource' and 'copy-left' principles practiced by certain communities of computer software developers (Kotschi and Rapf 2016). Also, several organic breeding initiatives (Osman and Chable 2009; Demeulenaere 2014; Wirz et al. 2017) have formed in reaction to the increasing commodification of seeds and varieties and/or to address related societal challenges, including negative effects on biodiversity, ecosystem services and human health (Lammerts van Bueren 2010; Lammerts van Bueren et al. 2011).

The perspective of Seed Commons challenges the dominant narrative that the best pathway towards food and nutrition security for the world's growing population is to foster privately-owned biotechnical innovations, supported by corresponding policy measures (see, for example, OECD 2018). It addresses major political impasses in the present international and national governance of varieties, seed and PGRFA that are based on such narratives and tend to be tailored towards the needs of private sector R\&D, largescale farms and 'industrial' food systems, hampering the necessary transition of farming and food systems towards more sustainable outcomes (IPES-Food 2016). By exploring innovative governance models for seed, varieties and PGRFA, Seed Commons could thus provide opportunities to reconsider how innovation could be fostered in a way to better serve current and future needs of farmers and society.

\section{Intention of the Symposium and approach taken}

The intention of the Symposium is to contribute to a deeper and more systematic understanding of material, knowledge, and cultural aspects of Seed Commons, including interactions and interdependencies between those aspects. It further 
aims to explore the perspectives Seed Commons can offer, especially with a view to current debates on how to design governance systems for seed, varieties and PGRFA in a way that they support the necessary transformation of farming and food systems towards more sustainable and equitable outcomes.

We first explore the concept of Seed Commons with its various interacting 'layers' and depict a set of core criteria on which Seed Commons rely. Subsequently, key insights from the research contributions selected for this Symposium are presented. Finally, we draw conclusions regarding the potential contributions of Seed Commons to sustainable farming and food systems.

\section{Conceptualizing Seed Commons}

Commons as such is a complex term that entails the relationships, forms of organization and interactions between humans and material or immaterial resources that are useful to them. The practices and processes through which a group of people interacts with a resource is a constitutive element of a commons (Linebaugh 2008; Helfrich et al. 2009). Typically, the user community itself establishes rules defining their interactions with each other and with the object/ resource in question, whereby these rules necessarily vary, depending on the users' individual and collective values, purposes and needs, and the characteristics of the resource.

The complex nature of seed and the fact that its governance takes place at various levels, from local to global, require that various commons categories be considered together to conceptualize Seed Commons (Sievers-Glotzbach et al. 2020). The collective management of the biophysical seed relates to the concept of traditional Natural Resource Commons (Ostrom 1990, 2005), the collective sharing of the associated knowledge to Knowledge Commons (Hess and Ostrom 2007; Frischmann et al. 2014), and the conservation and sustainable use of PGRFA to Global Commons (Joyner 2001; Mudiwa 2002). The social functions of local Seed Commons initiatives have been captured by recent conceptions of Commoning (Vivero-Pol 2017; Euler 2018).

Traditional Natural Resource Commons center on biophysical common-pool resources like fishing grounds, forests or grazing lands and their common-property regimes (Ostrom 1990; 2005). Seed Commons differ from those resources in various aspects. For example, as seed can be multiplied, varieties and seeds are considered to be 'non-subtractable' (Halewood 2013); use by one person does thus not limit others' possibilities of using seed of a specific variety, if necessary after further multiplication. While Seed Commons are related to certain agroecological conditions, they can be transferred to and used in other environments as well, even far away from where they originated. Such use may also include further breeding. The maintenance of Seed Commons depends strongly on active management by humans (Wilkes 1988; Fowler and Mooney 1990). Hence, the fundamental social dilemma is not the over-use of seeds and varieties, but their underprovision, a typical feature of Knowledge Commons and Global Commons.

Knowledge Commons are defined as the "the institutionalized community governance of the sharing and (...) creation, of information, science, knowledge, data, and other types of intellectual and cultural resources" (Frischmann et al. 2014). The generation of knowledge, and its sharing among users or across various actor groups, play a major role in breeding and seed production as well as in any kind of collective management of PGRFA.

PGRFA as expressions and carriers of genetic information and essential input to every breeding process have also been described as a Global Commons (Dedeurwaerdere 2013; Halewood 2013). Global Commons refer to arrangements of global collective action in international, supranational and global resource domains, such as the atmosphere or the deep sea (Joyner 2001; Mudiwa 2002). Whenever PGRFA, varieties and related knowledge are shared with a global user community, breeding and conservation efforts contribute to the maintenance and/or continual improvement of PGRFA as a Global Commons.

The concept of Commoning refers to commons as selforganized and needs-oriented social processes of peers (Euler 2018), shifting the focus from the management of specific resources to the social processes of community building. In this regard, relationships and values within Seed Commons communities and their social functions, such as democratic participation and autonomy or their potential for creating viable alternatives to privatization and commodification, are assessed (Euler 2018; ViveroPol et al. 2018). Collectively designed rules and norms are particularly important in the local management of seed and varieties, such as seed exchange networks, community seed banks and collaborative breeding initiatives. Tensions may arise if such local Seed Commons are negatively affected by national legal frameworks or international agreements (Santilli 2011).

Seed Commons are thus recognized to be highly complex, with diverse organizational forms, institutional settings, agroecological as well as socio-cultural contexts in which they are embedded. Nevertheless, all Seed Commons have been found to share four core features (Sievers-Glotzbach et al. 2020): (1) collective responsibility; (2) protection from private enclosure; (3) collective, polycentric management of seeds; and (4) sharing of knowledge and practical skills relating to breeding, seed management as well as cultivation and use (Fig. 1). 


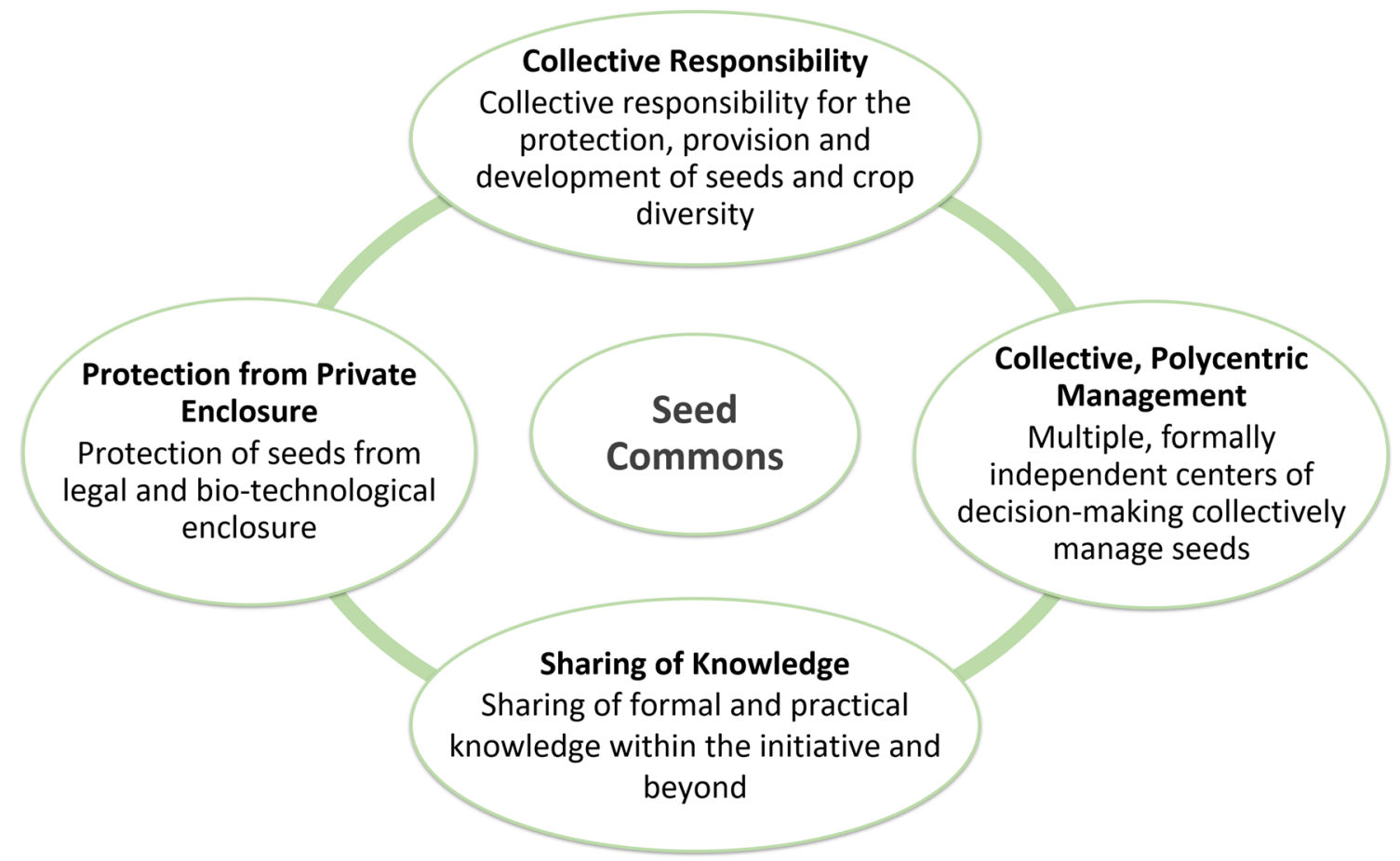

Fig. 1 Core criteria of Seed Commons (Sievers-Glotzbach et al. 2020)

Collective responsibility for the protection, provision and development of seeds and crop diversity has been recognized at the international level by the Contracting Parties to the ITPGRFA for some of the world's most important food and fodder crops (FAO 2009; Halewood 2013; Dedeurwaerdere 2013; Frison 2018). Other agricultural species fall under the Convention on Biological Biodiversity (CBD) and related protocols, e.g. the Nagoya Protocol on Access and Benefitsharing. National governments as well as regional organizations implement such commitments based on national laws, action plans and related programs for their implementation. At the local scale, Seed Commons such as community seed banks, seed exchange networks or collaborative breeding initiatives take on collective responsibility, e.g. for maintaining traditional landraces of relevance to them, or for jointly developing new varieties. Such initiatives may also be connected via national, regional or international associations or networks.

Seed Commons tend to reject private enclosure of products, such as plant variety protection and patents, as well as bio-technical methods that limit seed saving, exchange and use by farmers. Protection from private enclosure may secure the legal status of such products, e.g. against appropriation by others. For example, establishing local seed registries (Gómez César et al. 2017) or registerring varieties in national or regional seed catalogues in the name of a farmer organization or not-for-profit organization have been used as instruments to document collective 'ownership' of PGRFA, along with detailed descriptions of the variety in question (see examples presented by Halewood 2016). This type of documentation makes appropriation by third parties more difficult. Open-source seed models are also discussed and implemented as a specific instrument to protect varieties against future enclosure (Kloppenburg 2014; Kotschi and Horneburg 2018; Montenegro de Wit 2019).

Collective, polycentric management characterizes the organizational structure of rule-making in Seed Commons. While key goals, guiding principles and values may be agreed upon collectively, e.g. at the level of an association, the operational management of seed and varieties is organized in multiple substructures which hold independent decision-making power in many aspects. This form of organization strengthens grassroots democratic processes and re-distributes power in a way that needs of the respective user community are considered. Such decentralized network structures allow, for example, for regionally adapted breeding, need-oriented seed production, or for collective in-situ conservation of varieties that are perceived as valuable in specific contexts.

The sharing of knowledge plays a central role for the functioning of Seed Commons and includes scientific knowledge, e.g. on breeding methods, as well as practical knowledge and skills (Sievers-Glotzbach et al. 2020). The latter may include, for example, practical methods for assessing varieties or breeding lines, or for the multiplication and management of seed and planting material. Knowledge sharing in 
Seed Commons is often a corollary to the sharing of physical seed, in which such practical knowledge (e.g. selection skills of individual farmers or breeders) may be embedded. Knowledge may be shared within Seed Commons communities as well as beyond, e.g. through field visits, seed fairs, exhibitions etc. that are open to the general public.

\section{Seed Commons in this Symposium}

The organization of a Symposium to focus on Seed Commons was initiated in the spring of 2019 by calling for papers to explore Seed Commons from various perspectives. Contributions were invited from diverse disciplines and schools of thought in order to address conceptual aspects of Seed Commons, specifically from a 'New Commons' perspective; policy and governance aspects, including current and emerging forms of collaboration, governance, and institutions; philosophical and normative perspectives; and agroecological or socioeconomic outcomes and societal impacts. ${ }^{1}$

Individual contributions were selected that combine various perspectives and address challenges arising from the complex nature and multi-level governance of Seed Commons, as described above. Two articles focus on cross-cutting issues, namely knowledge (Sievers-Glotzbach et al.) and innovation (Beumer et al.), and how they are related with governance and organizational structures of Seed Commons.

All selected contributions are based on case studies, with both the Global-North (France, Netherlands, Germany) and South (Mali, Benin, Madagascar, Philippines) being represented. Diverse forms of Seed Commons were studied regarding their organizational structures and/or contributions to sustainable farming and food systems. The cases examined include organic and farmer-led breeding organizations, networks of farmer seed-cooperatives with public breeding programs, forms of cooperation between public and private actors in the development of new varieties and breeding technologies, and activities of local farming communities.

The Symposium thus begins to examine Seed Commons in their organizational and geographical diversity. By applying various theoretical approaches and frameworks, including Elinor Ostrom's (1990) ‘design principles', Institutional Analysis and Development (IAD) and Social-Ecological Systems (SES) frameworks (Ostrom 2009; Ostrom and Cox 2010; McGinnis and Ostrom 2014), it provides diverse entry points for exploring Seed Commons. Many of the contributions in this Symposium also refer to the more current understanding of Commoning as a social practice (Kostakis and Bauwens 2014; Euler 2018).

\footnotetext{
1 https://www.rightseeds.de/wp-content/uploads/2019/05/Call-forcontributions_Seed-Commons_final.pdf (4 July 2020).
}

Sievers-Glotzbach et al. ("Beyond the material: knowledge aspects in seed commoning") compare the ways that knowledge is managed and exchanged by Seed Commons at the international and local levels. The Multilateral System (MLS) of the ITPGRFA and associations of farmer-breeders in Germany (Kultursaat e.V.) and the Philippines (MASIPAG) are taken as examples. While seed samples made available via the MLS easily cross levels and boundaries between communities of actors operating at different levels, the exchange and flow of knowledge between those groups is limited by various factors, with important implications for the distribution of benefits and potential contributions to sustainable farming and food systems.

Halewood et al. ("Enhancing farmers' agency in the global crop commons through use of biocultural community protocols") present bio-cultural community protocols, developed with farming communities in Benin and Madagascar. These protocols establish the communities' self-determined rules for interactions with outsiders relating to PGRFA and/ or associated knowledge and are linked to the national legal systems of Access and Benefit-sharing. At the same time, the communities' access to PGRFA available from the MLS was facilitated through national genebanks and research organizations. Such activities contribute to strengthening the position of farming communities within the multi-layered local-to-global governance system of Seed Commons and have a potential to increase benefits for farmers from their countries' international commitments.

Mazé et al. ("Commoning the seeds: alternative models of collective action and open innovation for recreating local knowledge commons in France") study and compare the organizational rules and procedures for breeding and seed exchange of two local groups in the farmer seed-network, Réseau Semences Paysannes (RSP), in France. RSP emerged as an act of resistance to the ongoing commodification and private enclosure of agricultural seeds and varieties, with feared negative consequences for farmers and society, including loss of agricultural biodiversity and challenges for food sovereignty. The work of RSP is strongly based on ethical principles and values such as trust, reciprocity and mutual assistance. The governance rules developed by the farmer groups are investigated by using recent theoretical and analytical developments for Seed Commons (e.g. relating to the IAD/SES framework, mentioned above).

Rattunde et al. ("Transforming a traditional commonsbased seed system through collaborative networks of farmer cooperatives and public breeding programs: The case of sorghum in Mali") present recent developments in seed systems of sorghum, a traditional staple food crop in Mali. Sorghum seed in Mali has been traditionally managed as a commons by individual farmers and farming communities, with a strong notion that farm-saved seed, or seed received based on trusted relationships, best ensures food security. 
However, the development of new varieties to cope with rapidly changing environments and market-opportunities and organizing access to seed of these new varieties, especially beyond one's village and close family circles, required new organizational arrangements. The authors demonstrate how a decentralized system of variety testing, seed multiplication and dissemination was established that builds on farmer cooperatives as key actors. Respecting the farmers' own (commons-based) approaches and building on them was the basis for success.

The fact that innovation may challenge and transform existing governance structures is also addressed by Beumer et al. ("Innovation and the commons: lessons from the governance of genetic resources in potato breeding"). The authors highlight the issue that innovation can be facilitated by certain commons-based governance structures, while at the same time having an impact on or challenging such structures, causing re-arrangements. This study is based on the example of diploid hybrid potato breeding in the Netherlands, a new breeding technology with potentially farreaching impact on breeding approaches that have existed so far, and the respective governance structures. The authors thus draw attention to the different ways in which innovation, commons and its governance interact, and suggest that such socio-technical constellations are continuously co-produced.

\section{Conclusions and significance}

The contributions to this Symposium base their scientific analyses on various known frameworks for analyzing commons and integrate several aspects of commons that are relevant for understanding the specific features of seed, varieties and PGRFA, including the fact that human knowledge and values are 'embedded' in a biological asset (the seed), which is as such mobile and reproducible and can also be used for further breeding.

The possibility for farmers to share seed, along with practical skills and breeding knowledge, is a core element of seed and food sovereignty. It is therefore not surprising that such practices were found to be typical for Seed Commons in many countries (see case studies presented by SieversGlotzbach et al., Mazé et al. and Rattunde et al. in this issue), and can even become an expression of resistance if such activities are restricted by law or private enclosure (see Mazé et al. in this issue).

By shifting decision-making power to the local level, Seed Commons are particularly oriented to fulfilling the needs of specific user communities, e.g. farmers and consumers, as they evolve. Hence, taking responsibility for the protection, provision and development of crop diversity, combined with the collective governance of seeds and varieties in polycentric structures, can support social-ecological resilience in agricultural systems (Sievers-Glotzbach et al. 2020).

If local Seed Commons are embedded in strategic collaborations between government, civil society and farmer/ breeding communities, they can also serve a range of sustainability objectives in international food and biodiversity policies, and serve as a "political tool and horizon" (ViveroPol et al. 2018) for a larger social-ecological transformation in agricultural and food systems.

Even in settings where the private sector is involved in breeding and seed marketing, elements of Seed Commons can be relevant. The pooling of resources and capacities needed to achieve shared goals, including use of diverse PGRFA in breeding as discussed by Beumer et al. in this issue, is an example. Their observations on the interrelation between commons and innovation represent a timely contribution, especially since innovation is often associated with private 'entrepreneurship', rather than collective action (Allen and Potts 2016).

Major challenges arise from the integration of local Seed Commons into global governance structures for PGRFA (see Sievers-Glotzbach et al. and Halewood et al. in this issue), partly due to difficulties or objections to share knowledge across different actor groups. Publicly funded national research organizations, breeding programs or genebanks can play a constructive role as intermediaries in this regard, particularly if there is a willingness to address and shift power balances in the local-to-global governance system. Among the presented works, the case of bio-cultural community protocols in Benin and Madagascar (Halewood et al. in this issue) is exceptional in that such efforts have been acknowledged in the countries' legal systems.

In-depth studies of policy impacts on the development of Seed Commons are still rare. Chable et al. (2020) highlight the central role of seed laws for creating an enabling external environment, stating that "current seed laws and policies are not designed to promote diversity in agricultural systems". Supportive policies, conducive to Seed Commons and related social practices, are therefore particularly needed.

The Seed Commons framework with its four elements (see Fig. 1) could provide the foundation for the design of such policies. Specific policy elements supportive of Seed Commons include: Recognition of collective responsibility for seed and variety development, possibly including options for funding such activities for 'the greater public good'; Legal pathways for the protection of varieties from private enclosure and seed laws supporting the exchange of material among and between Seed Commons; Support for polycentric, collective management structures, such as locally based breeding initiatives with linkages between actors operating in different areas or at different levels, and; Support for effective knowledge-sharing activities in Seed Commons that cross boundaries between 'science' and 'practice'. 
Acknowledgements We thank the journal's former and current editorsin-chief, Prof. Harvey S. James Jr. and Prof. Matthew Sanderson, for the trustful cooperation over the time the Symposium evolved from an initial idea to the published issue. It has been elaborated as part of the research project 'Right Seeds? Common-based rights on seeds and seed varieties for a social-ecological transformation of plant cultivation', funded by the German Federal Ministry of Education and Research (BMBF) under the program 'Research for sustainable development (FONA)', funding reference: 01UU1602A/C.

Funding Open Access funding enabled and organized by Projekt DEAL.

Open Access This article is licensed under a Creative Commons Attribution 4.0 International License, which permits use, sharing, adaptation, distribution and reproduction in any medium or format, as long as you give appropriate credit to the original author(s) and the source, provide a link to the Creative Commons licence, and indicate if changes were made. The images or other third party material in this article are included in the article's Creative Commons licence, unless indicated otherwise in a credit line to the material. If material is not included in the article's Creative Commons licence and your intended use is not permitted by statutory regulation or exceeds the permitted use, you will need to obtain permission directly from the copyright holder. To view a copy of this licence, visit http://creativecommons.org/licenses/by/4.0/.

\section{References}

Allen, Darcy W.E.., and Jason Potts. 2016. How Innovation Commons Contribute to Discovering and Developing New Technologies. International Journal of the Commons 10 (2): 1035-1054.

Almekinders, Conny J. M., Graham Thiele, and Daniel L. Danial. 2007. Can Cultivars from Participatory Plant Breeding Improve Seed Provision to Small-Scale Farmers? Euphytica 153 (3): 363-372.

Aoki, Keith. 2009. 'Free Seeds, Not Free Beer': Participatory Plant Breeding, Open Source Seeds, and Acknowledging User Innovation in Agriculture. Fordham Law Review 77 (5): 2275-2310.

Barbieri, Pietro, and Stefano Bocchi. 2015. Analysis of the Alternative Agriculture's Seeds Market Sector: History and Development. Journal of Agricultural and Environmental Ethics 28 (4): 789-801.

Chable, Véronique., Edwin Nuijten, Ambrogio Costanzo, Isabelle Goldringer, Ricardo Bocci, Bernadette Oehen, Frédéric. Rey, Dionysia Fasoula, Judith Feher, Marjo Keskitalo, Beate Koller, Michalis Omirou, Pedro Mendes-Moreira, Gaëlle. van Frank, Abdel Kader Neino. Jika, Mathieu Thomas, and Adanella Rossi. 2020. Embedding Cultivated Diversity in Society for Agro-Ecological Transition. Sustainability 12 (3): 784.

Christinck, Anja, Marthe Diarra, and Gottfried Horneber. 2014. Innovations in Seed Systems: Lessons from the CCRP-Funded Project 'Sustaining Farmer-Managed Seed Initiatives in Mali, Niger, and Burkina Faso'. Minneapolis: The McKnight Foundation. www. mcknight.org/system/asset/document/850/original/CCRP_SeedS ystems_Nov2014.pdf. Accessed 28 July 2020.

Bonny, Sylvie. 2017. Corporate Concentration and Technological Change in the Global Seed Industry. Sustainability 9: 1632.

Coomes, Oliver T., J. Shawn, Eric Garine McGuire, Sophie Caillon, Doyle McKey, Elise Demeulenaere, Devra Jarvis, Guntra Aistara, Adeline Barnaud, Pascal Clouvel, Laure Emperaire, Selim Louafi, Pierre Martin, François Massol, Marco Pautasso, Chloé Violon, and Jean Wencelius. 2015. Farmer Seed Networks Make a Limited
Contribution to Agriculture? Four Common Misconceptions. Food Policy 56: 41-50.

Dawson, Julie C., Kevin M. Murphy, and Stephen S. Jones. 2008. Decentralized Selection and Participatory Approaches in Plant Breeding for Low-Input Systems. Euphytica 160 (2): 143-154.

Dedeurwaerdere, Tom. 2013. Institutionalizing Global Genetic Resource Commons for Food and Agriculture. In Crop Genetic Resources as a Global Commons: Challenges in International Law and Governance, ed. Michael Halewood, Isabel López Noriega, and Selim Louafi, 368-391. Abingdon, New York: Routledge.

Demeulenaere, Elise. 2014. A Political Ontology of Seeds: The Transformative Frictions of a Farmers' Movement in Europe. Journal of Global and Historical Anthropology 69: 45-61.

Euler, Johannes. 2018. Conceptualizing the Commons: Moving Beyond the Goods-Based Definition by Introducing the Social Practices of Commoning as Vital Determinant. Ecological Economics 143: $10-16$.

FAO. 2009. International Treaty on Plant Genetic Resources for Food and Agriculture. Rome: Food and Agriculture Organization of the United Nations (FAO).

FAO. 2019. The State of the World's Biodiversity for Food and Agriculture. FAO Commission on Genetic Resources for Food and Agriculture Assessments. Rome: Food and Agriculture Organization of the United Nations (FAO).

César, Gómez., Ronnie Vernooy Montserrat, and Bhuwon Sthapit. 2017. Safeguarding Local Crop Knowledge: The Use of Community Biodiversity Registers. Rome: Bioversity International.

Helfrich, Silke, Rainer Kuhlen, Wolfgang Sachs, and Christian Siefkes. 2009. Gemeingüter-Wohlstand Durch Teilen. Berlin: Heinrich Böll-Stiftung.

Ficiciyan, Anoush, Jacqueline Loos, Stefanie Sievers-Glotzbach, and Teja Tscharntke. 2018. More than Yield: Ecosystem Services of Traditional Versus Modern Crop Varieties Revisited. Sustainability 10: 2834.

Fowler, Cary, and Pat Mooney. 1990. Shattering: Food, Politics, and the Loss of Genetic Diversity. Tucson: University of Arizona Press.

Frischmann, Brett M., Michael J. Madison, and Katherine Jo Strandburg (eds.). 2014. Governing Knowledge Commons. Oxford, New York: Oxford University Press.

Frison, Christine. 2018. Planting the Commons: Towards Redesigning an Equitable Global Seed Exchange. In The Commons, Plant Breeding and Agricultural Research: Challenges for Food Security and Agrobiodiversity, ed. Fabien Girard and Christine Frison, 272-290. New York: Routledge.

Girard, Fabien, and Christine Frison (eds.). 2018. The Commons, Plant Breeding and Agricultural Research: Challenges for Food Security and Agrobiodiversity. New York: Routledge.

Halewood, Michael. 2013. What Kind of Goods are Plant Genetic Resources for Food and Agriculture? Towards the Identification and Development of a New Global Commons. International Journal of the Commons 7: 278-312.

Halewood, Michael (ed.). 2016. Farmers' Crop Varieties and Farmers' Rights. Challenges in Taxonomy and Law. Abingdon/New York: Routledge.

Hess, Charlotte, and Elinor Ostrom (eds.). 2007. Understanding Knowledge as a Commons: From Theory to Practice. Cambridge: Massachusetts Institute of Technology (MIT) Press.

Howard, Philip H. 2015. Intellectual Property and Consolidation in the Seed Industry. Crop Science. https://doi.org/10.2135/ CROPSCI2014.09.0669.

IPES-Food. 2016. From Uniformity to Diversity: A Paradigm Shift from Industrial Agriculture to Diversified Agroecological Systems. Brussels: International Panel of Experts on Sustainable Food Systems (IPES-Food). https://www.ipes-food.org/_img/ 
upload/files/UniformityToDiversity_FULL.pdf. Accessed 27 July 2020.

IPES-Food. 2017. Too Big to Feed: Exploring the Impacts of MegaMergers, Consolidation and Concentration of Power in the Agri-Food Sector. Brussels: International Panel of Experts on Sustainable Food Systems (IPES-Food). https://www.ipes-food. org/_img/upload/files/Concentration_FullReport.pdf. Accessed 27 July 2020.

Joyner, Christopher C. 2001. Global Commons: The Oceans, Antarctica, the Atmosphere, and Outer Space. In Managing Global Issues: Lessons Learned, ed. Peter J. Simmonds, and Chantal de Jonge Oudraat, 354-391. Washington D.C.: Carnegie Endowment for International Peace.

Kloppenburg, Jack. 2014. Re-Purposing the Master's Tools: The Open Source Seed Initiative and the Struggle for Seed Sovereignty. Journal of Peasant Studies 41 (6): 1225-1246.

Kostakis, Vasilis, and Michel Bauwens. 2014. Network Society and Future Scenarios for a Collaborative Economy. Basingstoke/New York: Palgrave Pivot Palgrave Macmillan.

Kotschi, Johannes, and Bernd Horneburg. 2018. The Open Source Seed Licence: A Novel Approach to Safeguarding Access to Plant Germplasm. PLoS Biology. https://doi.org/10.1371/journal.pbio.3000023.

Kotschi, Johannes, and Klaus Rapf. 2016. Liberating Seeds with an Open Source Seed Licence. Association for AgriCulture and Ecology (AGRECOL). https://www.opensourceseeds.org/sites/default/files /downloads/Liberating_seeds_with_an_Open_Source_Seed_licen ce.pdf. Accessed 28 July 2020.

Lammerts van Bueren, Edith. 2010. Ethics of Plant Breeding: The IFOAM Basic Principles as a Guide for the Evolution of Organic Plant Breeding. Ecology and Farming 2010 (February): 7-10.

Lammerts van Bueren, Edith T, Sam S. Jones, Lucius Tamm, and Kevin Murphy. 2011. The Need to Breed Crop Varieties Suitable for Organic Farming, Using Wheat, Tomato and Broccoli as Examples: A Review. NJAS Wageningen Journal of Life Sciences 58: 193-205.

Linebaugh, Peter. 2008. The Magna Carta Manifesto: Liberties and Commons for All. Berkeley/Los Angeles/London: University of California Press.

McGinnis, Michael D., and Elinor Ostrom. 2014. Social-Ecological System Framework: Initial Changes and Continuing Challenges. Ecology and Society 19 (2): 30

Montenegro de Wit, Maywa. 2019. Beating the Bounds: How Does 'Open Source' Become a Seed Commons? Journal of Peasant Studies 46 (1): 44-79.

Mudiwa, Morris. 2002. Global Commons: The Case of Indigenous Knowledge, Intellectual Property Rights and Biodiversity. The Commons in an Age of Globalisation, the Ninth Biennial Conference of the International Association for the Study of Common Property. https://hdl.handle.net/10535/428. Accessed 27 July 2020.

OECD. 2018. Concentration in Seed Markets: Potential Effects and Policy Responses. Paris: Organisation for Economic Co-operation and Development (OECD) Publishing. https://www.oecd.org/publi cations/concentration-in-seed-markets-9789264308367-en.htm. Accessed 27 July 2020.

Osman, Aart M., and Veronique Chable. 2009. Breeding Initiatives of Seeds of Landraces, Amateur Varieties and Conservation Varieties: An Inventory and Case Studies. Driebergen: Louis Bolk Instituut. https://edepot.wur.nl/51434. Acessed 28 July 2020.

Ostrom, Elinor. 1990. Governing the Commons: The Evolution of Institutions for Collective Action. Cambridge: Cambridge University Press.

Ostrom, Elinor (ed.). 2005. Understanding Institutional Diversity. Princeton: Princeton University Press.

Ostrom, Elinor. 2009. A General Framework for Analyzing Sustainability of Social-Ecological Systems. Science 325: 419-422.

Ostrom, Elinor, and Michael Cox. 2010. Moving Beyond Panaceas: A Multi-tiered Diagnostic Approach for Social-Ecological Analysis. Environmental Conservation 37 (4): 451-463.
Pautasso, Marco, Guntra Aistara, Adeline Barnaud, Sophie Caillon, Pascal Clouvel, Oliver T. Coomes, Marc Delêtre, Elise Demeulenaere, Paola De Santis, Thomas Döring, Ludivine Eloy, Laure Emperaire, Eric Garine, Isabelle Goldringer, Devra Jarvis, Hélène. I. Joly, Christian Leclerc, Selim Louafi, Pierre Martin, François Massol, Shawn McGuire, Doyle McKey, Christine Padoch, Clélia. Soler, Mathieu Thomas, and Sara Tramontini. 2013. Seed Exchange Networks for Agrobiodiversity Conservation A Review. Agronomy for Sustainable Development 33 (1): 151-175.

Santilli, Juliana. 2011. Agrobiodiversity and the Law. Regulating Genetic Resources, Food Security and Cultural Diversity. Abingdon/New York: Routledge.

Schapiro, Mark. 2018. Seeds of Resistance. The Fight to Save our Food Supply. New York: Skyhorse Publishing.

Schöley, Michaela, and Martina Padmanabhan. 2017. Formal and Informal Relations to Rice Seed Systems in Kerala, India: Agrobiodiversity as a Gendered Social-Ecological Artifact. Agriculture and Human Values 34: 969-982.

Sievers-Glotzbach, Stefanie, Julia Tschersich, Nina Gmeiner, Lea Kliem, and Anoush Ficiciyan. 2020. Diverse Seeds-Shared Practices: Conceptualizing Seed Commons. International Journal of the Commons. https://doi.org/10.5334/ijc. 1043.

Sperling, Louise, A. Ashby. Jacqueline, Margaret E. Smith, Eva Weltzien, and Shawn McGuire. 2001. A Framework for Analyzing Participatory Plant Breeding Approaches and Results. Euphytica 122: 439-450.

Thomas, Mathieu, Julie C. Dawson, Isabelle Goldringer, and Christophe Bonneuil. 2011. Seed Exchanges, A Key to Analyze Crop Diversity Dynamics in Farmer-led on-Farm Conservation. Genetic Resources and Crop Evolution 58 (3): 321-338.

Vernooy, Ronnie, Bhuwon Sthapit, Gea Galluzzi, and Pitambar Shrestha. 2014. The Multiple Functions and Services of Community Seedbanks. Resources 3: 636-656.

Vivero-Pol, José Luis. 2017. Food as Commons or Commodity? Exploring the Links Between Normative Valuations and Agency in Food Transition. Sustainability 9 (3): 442.

Vivero-Pol, José Luis, Tomaso Ferrando, Olivier De Schutter, and Ugo Mattei. 2018. Introduction-The Food Commons Are Coming... In Routledge Handbook of Food as a Commons: Expanding Approaches, ed. José Luis Vivero-Pol, Tomaso Ferrando, Olivier De Schutter, and Ugo Mattei, 1-22. Abingdon/New York: Routledge.

Wilkes, H. Garrison. 1988. Plant Genetic Resources Over Ten Thousand Years: From a Handful of Seed to the Crop Specific Mega Genebank. In Seeds and Sovereignty: The Use and Control of Plant Genetic Resources, ed. J.R. Kloppenburg, 67-89. Durham: Duke University Press.

Wirz, Johannes, Peter Kunz, and Ueli Hurter. 2017. Saatgut_Gemeingut, Züchtung als Quelle von Realwirtschaft, Recht und Kultur. Dornach: Verlag am Goetheanum.

Publisher's Note Springer Nature remains neutral with regard to jurisdictional claims in published maps and institutional affiliations.

Stefanie Sievers-Glotzbach is junior professor at the University of Oldenburg, Department of Business Administration, Economics and Law, and leads the research group RightSeeds, funded by the German Federal Ministry of Education and Research (BMBF). She holds a $\mathrm{Ph} . \mathrm{D}$. in Sustainability Sciences and a Diploma degree in Environmental Sciences, both from Leuphana University, Lüneburg. She was a researcher in the Ecological Economics group at Oldenburg University from 2012 to 2015, and the academic advisor of the master program 'Sustainability Economics and Management'. Her research interests include ecological, institutional and sustainability economics, sustainable development, environmental justice, and socio-ecological resilience 
research. Her present research focusses on commons as a governance model and its potential for social-ecological transformation.

Anja Christinck (Ph.D.) is an agronomist with specialization in agricultural social sciences and communication. Her scientific work focusses on participatory and transdisciplinary research on agrobiodiversity, plant breeding and seed system development in the context of international development-oriented agricultural research. She contributes to scientific policy advice on issues relating to intellectual property rights for plant varieties and seeds, human rights and rights of farmers through consultancies to the German Federal Parliament, various ministries, international donor organizations and FAO. Besides her thematic expertise, she has lengthy experience as an author, reviewer and editor of publications, conference proceedings and books. 